\title{
SEM-EDX Analysis of Laser Surface Alloying on Aluminum
}

\author{
Noriah Bidin $^{1}$, Mundzir Abdullah ${ }^{1}$, Mohd Syafik Shaharin ${ }^{1}$, Yusef Abdul Alwafi ${ }^{1}$, \\ Dwi Gustiono Riban ${ }^{2}$ \& Moh Yasin ${ }^{1,3}$ \\ ${ }^{1}$ Advanced Photonic Science Institute, Faculty of Science, \\ University Teknologi Malaysia, Skudai 81300, Malaysia \\ ${ }^{2}$ Ibnu Sina Institute for Fundamental Science Studies, \\ Universiti Teknologi Malaysia, 81310 UTM Skudai, Johor, Malaysia \\ ${ }^{3}$ Department of Physics, Faculty of Science and Technology, \\ Airlangga University, Jalan Mulyorejo, Surabaya 60115, Indonesia \\ E-mail: noriah@utm.my
}

\begin{abstract}
Microstructure and chemical composition changes on the alloyed aluminum surface were investigated using SEM-EDX analysis. A Q-switched $\mathrm{Nd}$ :YAg laser was focused to induce breakdown and plasma formation. The high plasma temperature and the shock wave pressure were responsible for speeding up the laser surface alloying process. The rapid heat and cooling process introduced a non-equilibrium condition causing changes in the microstructure as well as the chemical composition of the alloyed aluminum surface. The remelted layer and molten pools were realized after the aluminum received a power density greater than $5 \times 10^{8} \mathrm{Wcm}^{-2}$. The chemical composition change confirms that the convection process had taken place during the alloying process.
\end{abstract}

Keywords: chemical composition; Fe-Cu powder; intermetallics phase; laser alloying; microstructure.

\section{Introduction}

Laser is a powerful tool that can be used to improve surface properties such as hardness and wear resistance by modifying the composition and/or microstructure of the surface without affecting the properties of the bulk material. The interaction time between the material and laser beam leads to several processes. These processes are due to different combinations of absorption, heat conduction, melting, powder addition, and rapid solidification [1]. Among the various materials, aluminum is used in industry for various applications due to its low cost, light weight and excellent workability, but it lacks in wear resistance and hardness. Many studies have been carried out to improve the surface properties of aluminum by adding a powder of various materials, such as $\mathrm{Fe}, \mathrm{Ni}, \mathrm{Mo}, \mathrm{Cr}, \mathrm{Ti}$, or $\mathrm{Cu}, \mathrm{Si}$ [2-6]. Laser surface alloying is considered to be the most effective technique for surface modification [7-11]. However, systematic investigation of the microstructure and the change in

Received 22 January 2012, $1^{\text {st }}$ Revision 5 September 2012, $2^{\text {nd }}$ Revision 8 December $2012,3^{\text {rd }}$ Revision 5 February 2013, Accepted publication 22 February 2013

Copyright () 2013 Published by ITB Journal Publisher, ISSN: 2337-5760, DOI: 10.5614/j.math.fund.sci.2013.45.1.5 
chemical composition has received little attention. Hence, in the present paper we intend to demonstrate the effect of the laser parameters on the microstructure and chemical composition of the modified $\mathrm{Al}$ surface.

\section{$2 \quad$ Experiment}

A Q-switched Nd:YAG laser with a fundamental wavelength of $1064 \mathrm{~nm}$, operated in repetitive mode at $1 \mathrm{~Hz}$, was used as the energy source. The laser pulse duration was 10 nanoseconds and the output energy remained constant at $93 \mathrm{~mJ}$ per pulse. The laser was focused using a convex lens of $30 \mathrm{~cm}$ focal length to induce optical breakdown and plasma formation. In order to enlarge the laser spot area, the target was located at a defocused distance, about $20 \mathrm{~mm}$ away from the focal point. In this position the power density was estimated to be $1.31 \times 10^{8} \mathrm{Wcm}^{-2}$ per pulse. A quench rate can be reached in the range of $2-4 \times 10^{7} \mathrm{~K} / \mathrm{s}$, corresponding to the lifetime of plasma radiation in air within the range of 300-500 $\mu$ s. The whole experimental setup used in this study has been described elsewhere [11].

A pure aluminum plate was used as the substrate. Iron-copper $(\mathrm{Fe}-\mathrm{Cu})$ mixtures with weight/weight ratio 2:1 were used as the alloying elements. The aluminum surface was painted with glue prior to spraying it with the alloying elements. The coated surface was then treated by a series of pulses (1- 4 pulses equivalent to a power density of 1-6 $\times 10^{8} \mathrm{Wcm}^{-2}$ ) from the focused beam of the Qswitched Nd:YAG laser.

A glow discharge spectrometer (GDS) was employed to evaluate the distribution of the alloyed elements within the skin depth of the surface layer. The microstructure of the alloyed samples was characterized by using an optical scanning electron microscope (SEM). The chemical composition changes of the modified aluminum surface were analyzed using energy dispersive $\mathrm{x}$-ray spectroscopy (EDXS).

\section{$3 \quad$ Results and Discussion}

It is important to note that the plasma temperature $(\sim 11,000 \mathrm{~K})$ is much higher than the melting points each of the alloying elements deposited on the aluminum surface. Hence, after laser interaction with the powders that are coated on the aluminum surface, the absorbed energy decomposes the metal grains and dissolves the metals into the aluminum substrate, thus forming the surface alloy. The plasma dynamically expands in the free surface within 300 to $500 \mu$ s depending on the delivering energy at the focal point. This implies that the higher the laser energy, the longer the lifetime of the plasma formation. However, in reality such microsecond lifetimes of plasma formation are still 
considerably short. The advantage of such a short plasma lifetime is that it introduces a rapid cooling or quenching in the alloying process. Such high speed alloying processes can control the heat dissipation in the bulk of the aluminum base. Furthermore, laser induced plasma is associated with the generation of acoustic shock waves that propagate with the speed of sound in the medium [12]. This allows the acceleration of the heat transfer into the target via convection. Such mechanisms contribute to rapid melting and cooling of all target elements, including the matrix materials. This leads to the formation of an alloyed layer within the skin depth region.

This phenomenon can be confirmed by analyzing the alloyed surface with a glow discharge spectroscopy, GDS machine. A typical GDS result of the tested samples is shown in Figure 1. Figure 1(a) indicates the element distribution of the aluminum substrate before coating and untreated by laser radiation. One hundred percent of the surface as well as the bulk contained $\mathrm{Al}$ elements apart from a few other elements, like $\mathrm{N}, \mathrm{Fe}_{2}, \mathrm{Cr}$ and $\mathrm{C}$. Figure 1(b) shows the distribution of Fe elements (50\%) and copper (almost 30\%) on the surface. The graph also indicates the penetration of Fe elements into the aluminum bulk. The Fe elements were defused into the bulk due to the heat transfer via convection of the melt pool of Al. The Fe elements were diffused within a skin depth of 25 $\mu \mathrm{m}$ and the $\mathrm{Cu}$ elements almost $15 \mu \mathrm{m}$ in the bulk of Al. The skin depth of the modified surface was also controlled by the quenching rate.

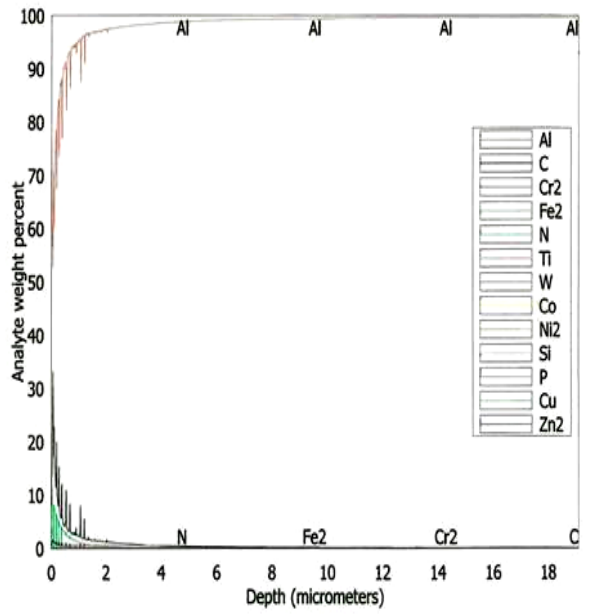

(a)

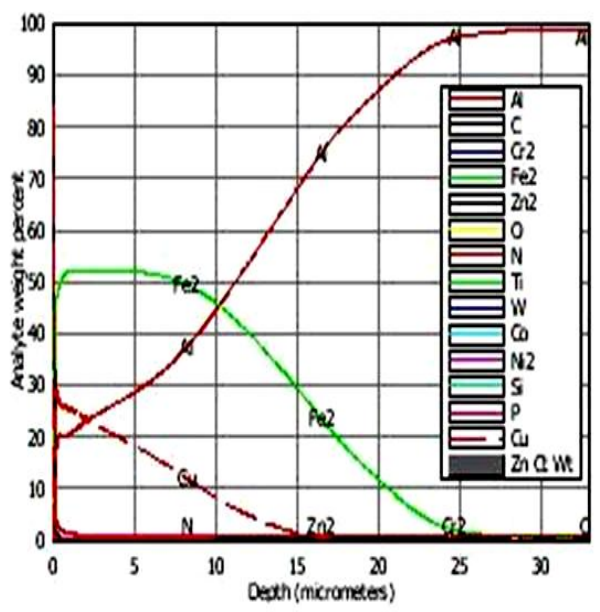

(b)

Figure 1 GDS analysis on (a) Al matrix, (b) $\mathrm{Al}$ coating with $\mathrm{Fe}-\mathrm{Cu}$ powder.

The rapid quenching rate contributed to non-equilibrium conditions in the aluminum base. This led to the formation of new alloy elements and hence 
changed the microstructure of the solidified surface layer as well as the chemical composition of the alloyed surface. The formation of the new alloyed elements was further validated via SEM examination and EDX analysis. The microstructure of the alloyed aluminum before laser treatment was examined with SEM, as shown in Figure 2(a). The $\mathrm{Fe}$ and $\mathrm{Cu}$ are clearly observable as individual particles on the $\mathrm{Al}$ matrix. The spectrum of the chemical composition of the coating material on the Al matrix is shown in Figure 2(b) and detailed weight percentages for each element analyzed with EDX spectroscopy are listed in Table 1. In a circle remarked, the dark grey indicates the Fe elements, whereas the white indicates $\mathrm{Cu}$ elements. Table 1 shows that the weight percentage of iron is remarkably high, but zero for copper. Chlorine exists due to the gum material used to adhere the coating material to the Al matrix.

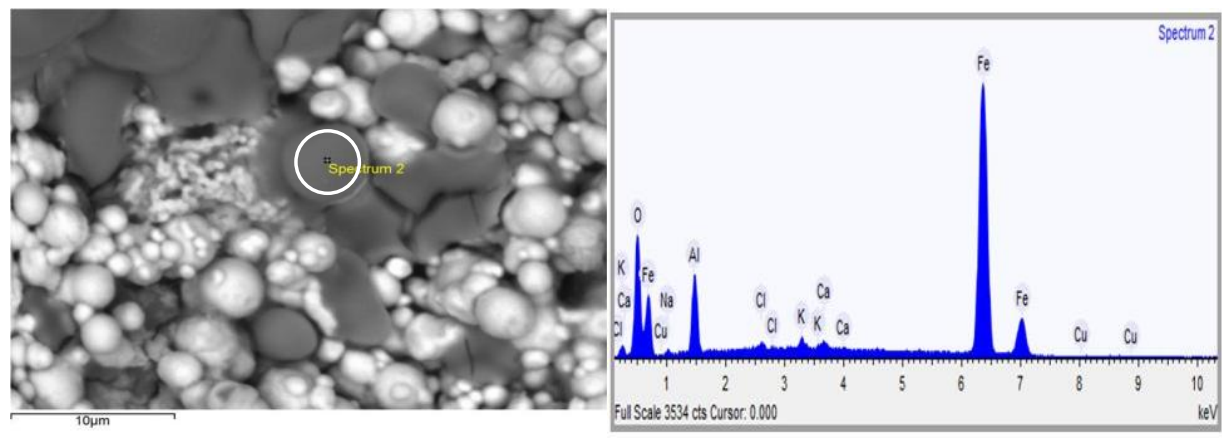

(a)

(b)

Figure 2 (a) Microstructure of sample before treatment. (b) Spectrum of EDX analysis before laser treatment.

Table 1 EDX analysis on no pulse target.

\begin{tabular}{cc}
\hline Element & Weight \% \\
\hline Oxygen & 14.807 \\
Sodium & 0.769 \\
Aluminum & 5.608 \\
Chlorine & 0.484 \\
Potassium & 0.846 \\
Calcium & 0.474 \\
Iron & 77.013 \\
Copper & 0.000 \\
\hline
\end{tabular}

Figure 3 depicts the microstructure of the alloyed surface after exposure by a series of pulses. Initially the sample was exposed to a single pulse (Figure 3(a)). Each pulse delivered a power density of $1.31 \times 10^{8} \mathrm{Jcm}^{-2}$. This power was enough to melt and re-solidify the alloyed elements. As the power density increased, the remelted layer expanded, as depicted in Figure 3(b), (c) and (d). Significant heavy remelting is shown in Figure 3(c). Almost all the alloyed 
elements were blended together to form new intermetalics phases or new composites. Despite experiencing a metastable phase transition, in the $\mathrm{Al}$ matrix also molten pools were created around the heating zone, as marked by the white arrow in Figure 3(d).

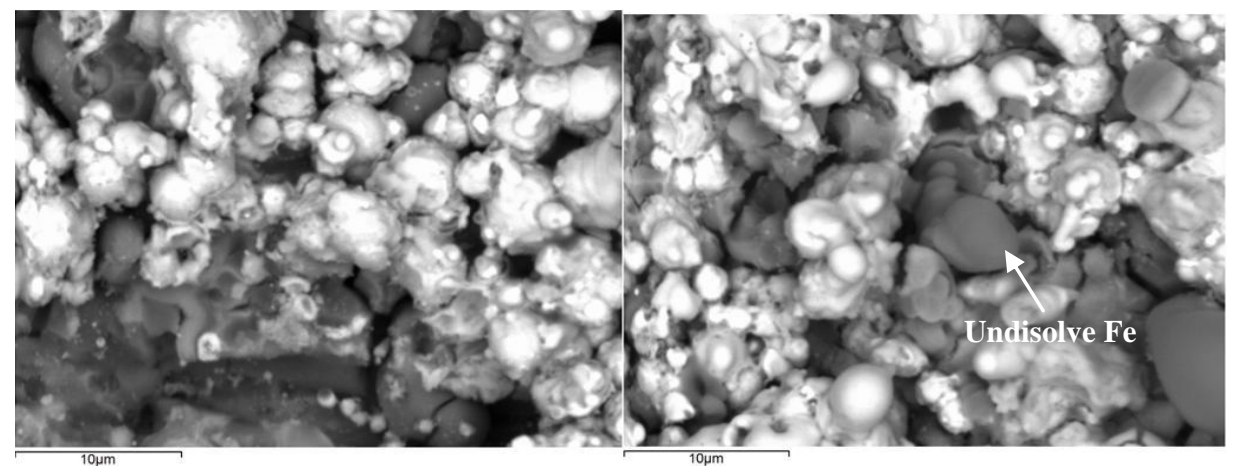

(a)

(b)

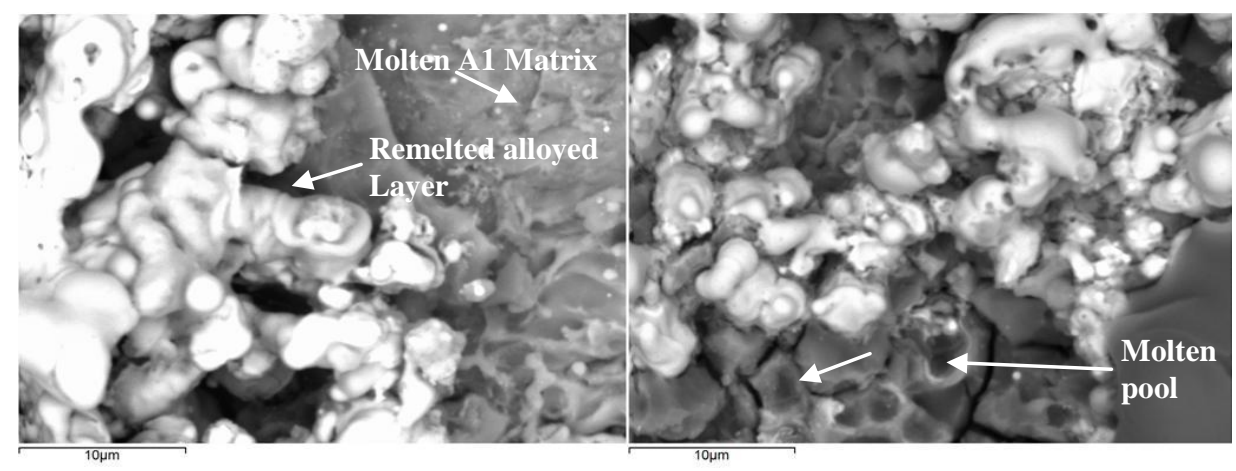

(c)

(d)

Figure 3 Microstructure of $\mathrm{Fe}-\mathrm{Cu}(2: 1)$ at different pulses: (a) 1 pulse, (b) 2 pulses, (c) 3 pulses, (d) 4 pulses.

The spectrum of the chemical composition resulting from the EDX analysis is shown in Figure 4, arranged according to the increasing number of pulses. Each of the constituents is the average from the scanning electron image. This analysis corresponds to the conventional process. This means that with a low power density, only a small area was melted and subsequently involved only small chemical composition changes. Apperantly, as more power was delivered to the surface, more heavy elements like $\mathrm{Cu}$ and Fe sank into the bulk. Consequently, only a small amount of chemical constituents could be traced. As a result, the $\mathrm{Al}$ elements rose up, but the Fe elements sank down and even ellimanted the copper elements, because they sank deeper into the Al bulk. The detailed chemical composition changes with respect to the various exposures are tabulated in Table 2. 
Table 2 Constituents of alloyed layer via EDX analysis.

\begin{tabular}{lcccc}
\hline \multirow{2}{*}{ Element } & \multicolumn{4}{c}{ Weight \% } \\
\cline { 2 - 5 } & 1 pulse & 2 pulses & 3 pulses & 4 pulses \\
\hline Oxygen & 27.469 & 29.843 & 21.691 & 68.655 \\
Magnesium & 0.937 & 1.738 & - & 0.449 \\
Aluminum & 26.096 & 5.290 & 43.228 & 22.843 \\
Chlorine & 2.147 & 4.555 & 1.844 & - \\
Iron & 43.241 & 58.139 & 32.238 & 2.5057 \\
Copper & 0.110 & 0.435 & 0.000 & 0.000 \\
\hline
\end{tabular}
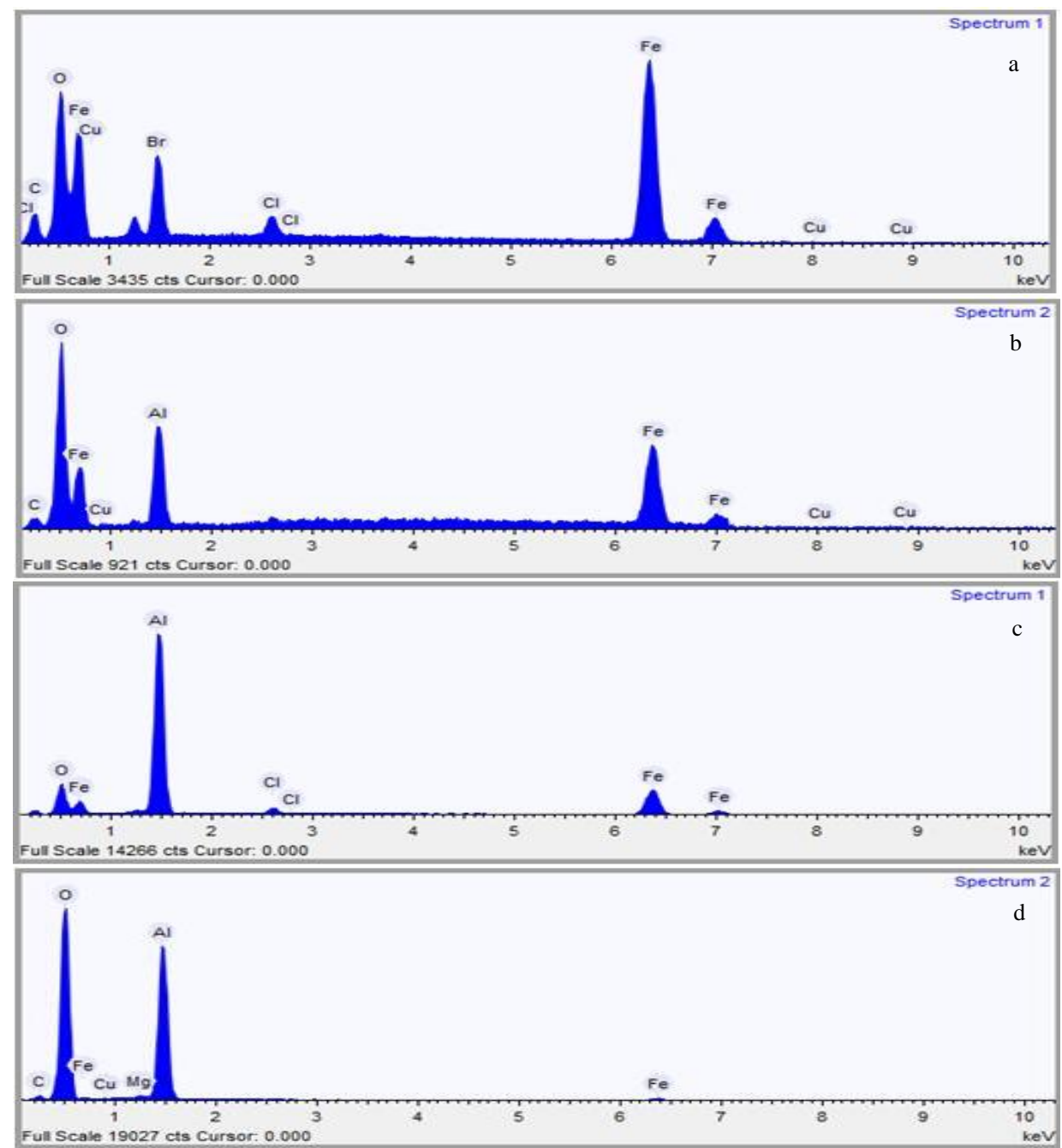

Figure 4 Spectrum of chemical composition via EDX analysis at various pulses: (a) 1 pulse, (b) 2 pulses, (c) 3 pulses, (d) 4 pulses. 


\section{Conclusion}

The microstructure of aluminum alloyed with $\mathrm{Fe}-\mathrm{Cu}$ has been investigated using SEM-EDX analysis. The aluminum was alloyed using the laser induced plasma technique. The plasma temperature was energetic enough to vaporize the skin depth layer resulting in melting and re-solidifying of the aluminum surface after the laser pulse had ceased. The SEM results show that the microstructure drastically changed with the energy density. Most of the exposed elements were melted and formed new composites, while molten pools were created close to the interaction zone after receiving a power density greater than $5 \times 10^{8} \mathrm{Wcm}^{-2}$. Meanwhile, the EDX analysis shows that the chemical composition of the modified surface had changed, which confirms that a convection process took place during the alloying process.

\section{Acknowledgements}

This project was supported by the Malaysian Ministry of Higher Education (MOHE) through Research University Grant vote $7126.00 \mathrm{H} 10$ and FRGS vote 4F001. Thanks are also due to UTM through RMC for financial management and project monitoring.

\section{References}

[1] Vaziri, A. \& Shahverdi, H.R., Effect of Beam Interaction Time on Laser Alloying with Pulsed Nd-YAG Laser, Materials Science and Technology 25(10), pp. 1234-1237, 2009.

[2] Tomida, S. \& Nakata, K., Fe-Al Composite Layers on Aluminum Alloy Formed by Laser Surface Alloying with Iron Powder, Surface and Coating Technology, 174, pp. 559-563, 2003.

[3] Poire, L. \& Blank, E., Laser Cladding of Copper Base Alloys onto Al Si $M g_{0.3}$, Journal De Physique IV, 4, pp. 81-84, 1994.

[4] Gaffet, E., Pelletier, J.M. \& Bonnet-Jobez, S., Precipitation of Cr-rich Phases in a Ni-50 Al- $2 \mathrm{Cr}$ (at \%) Alloy, Acta Metall, 37, pp. 3205-3215, 1989.

[5] Temizel, G. \& Ozenbas, M., Intermetallic Phase Formation at Fe-Al Film Interfaces, Turkish J. Engineering and Environmental Sciences, 31, p. 71, 2007.

[6] Su, R. \& Lei, Y., Microstructure and Hardness of Laser Clad Sicp-Al Composite Coatings on Al Alloys, Materials Letters., 62, pp. 3272-3275, 2008 .

[7] El-Batahgy, A. \& Kutsuna, M., Laser Beam Welding of AA5052, AA5083, and AA6061 Aluminum Alloys, Advances in Materials Science and Engineering, 2009, pp. 1-9, 2009. 
[8] Mabhali, L.A.B., Pityana, S.L. \& Sacks, N., Laser Surface Alloying of Aluminum (AA1200) with $\mathrm{Ni}$ and SiC Powders, Materials and Manufacturing Processes, 25(12), pp. 1397-1403, 2010.

[9] Popoola, A.P.I., Pityana, S.L. \& Popoola, O.M., Laser Deposition of ( $\mathrm{Cu}$ + Mo) Alloying Reinforcements on AA1200 Substrate for Corrosion Improvement, Int. J. Electrochem. Sci., 6, pp. 5038-5051, 2011.

[10] Nath, S., Pityana, S. \& Majumdar, J.D., Laser Surface Alloying of Aluminium with WC+Co+Nicr for Improved Wear Resistance, Surface \& Coatings Technology, 206(15), pp. 3333-3341, 2012.

[11] Alwafi, Y.A., Bidin, N. Gustiono D. \& Harun S.W., Alloying Aluminum with Fe Using Laser Induced Plasma Technique, Laser Physics, 22(8), pp. 1364-1367, 2012.

[12] Manalu, J.L., Kurniawan, K.H. \& Lie, T.J., Excitation Mechanism in Laser-Induced Plasma at Atmospheric Air Pressure, PROC. ITB Sains \& Tek., 37A(1), pp. 1-12, 2005. 